\title{
Links and risks associated with adenotonsillectomy and obesity
}

This article was published in the following Dove Press journal:

Pediatric Health, Medicine and Therapeutics

5 August 2015

Number of times this article has been viewed

\section{Arzu Tatlıpınar \\ Emrah Kınal}

ENT Clinic, Fatih Sultan Mehmet Research and Training Hospital, Kozyatağı, İstanbul, Turkey
Correspondence: Arzu Tatlıpınar ENT Clinic, Fatih Sultan Mehmet Research and Training Hospital, Kozyatağı, İstanbul, Turkey Tel +90532227 6657

Fax +90 2I2 2II 2500

Email arzutatli@yahoo.com
Abstract: Adenotonsillectomy (A\&T) is a very common surgical procedure in children. Over the past 20 years the principal indication for A\&T in children has changed from recurrent adenotonsillitis to obstructive sleep apnea. The physiopathology of obstructive sleep apnea syndrome (OSAS) is multifactorial and obesity has been shown to be one of the main factors correlated with its occurrence. On the other hand, the prevalence and severity of childhood obesity have become a veritable epidemic problem in the past 30 years. So the increasing prevalence of obesity in children and high prevalence of obstructive sleep apnea in obese children implies that an increasing number of these children will present for A\&T. Due to more prevalent anatomical alterations of the oronasopharyngeal airways, it is often difficult to predict operation success in obese children. However, previous studies supports that although the risk of presence of residual symptoms of OSAS and airway-related perioperative complication in obese may be more than nonobese group, A\&T is effective to reduce obstructive symptoms and improve quality of life in obese children with OSAS.

Keywords: obesity, adenotonsillectomy, obstructive sleep apnea syndrome

\section{Introduction}

Pediatric sleep disordered breathing (SDB) is caused by a combination of increased upper airway resistance and repetitive pharyngeal collapsibility, resulting in intermittent hypoxemia and arousal from sleep. ${ }^{1}$ SDB with associated apneas or hypopneas affects between $1 \%$ and $3 \%$ of children and is called obstructive sleep apnea syndrome (OSAS). ${ }^{2}$ The main cause of SDB in children is adenotonsillar hypertrophy. ${ }^{3,4}$ However, obesity is known to be another risk for SDB. The prevalence and severity of childhood obesity have become a veritable epidemic problem in the past 30 years. Hence, this worldwide epidemiologic evidence leads to a corresponding increase in the prevalence of diseases including SDB. Previous studies showed that severity of obstructive sleep apnea (OSA) seems to be proportional to the degree of obesity. ${ }^{5-7}$ The risk of SDB has been reported to be 4.6-fold higher among obese than in normal-weight children aged 2-18 years, with the risk of SDB increasing by $12 \%$ for every $1 \mathrm{~kg} / \mathrm{m}^{2}$ body mass index (BMI) increment above mean BMI 0.5. If children with SDB, especially in its OSAS form, are not treated or treated too late, they may develop high morbidity. ${ }^{8}$ It has been shown that untreated OSA is associated with adverse cardiovascular, neurocognitive, and somatic growth consequences. ${ }^{9-13}$

In a recent review, Arens et al established a clear definition of different phenotypes of OSAS in children. ${ }^{6}$ According to this definition there would be four reasons which are associated with OSAS. These are adenotonsillar hypertrophy and increased 
collapsibility of the upper airways, craniofacial malformations and certain syndromes (Down syndrome and PierreRobin syndrome), primary neuromuscular disorders, and obesity. The prevalence of OSAS among obese children seems to be higher than that of other phenotype and could increase the risk more than four times. ${ }^{14,15}$

\section{Diagnosis}

Accurate diagnosis of OSAS is made with polysomnography (PSG), but this is not easily employed, is expensive, and usually not possible at office practices. Due to PSG's disadvantages, answers provided via a symptom questionnaire, physical examination findings, lateral radiographs, fiberoptic endoscopy, and acoustic rhinometry have been advocated as reliable in detecting the adenotonsillar hypertrophy and its connection to upper airway obstruction. ${ }^{16-19}$ Hence, all these methods can be used to decide about the treatment options (observation or surgery).

\section{OSAS and obesity}

The prevalence of OSA in obese children appears to be between $30 \%$ and $40 \%{ }^{20,21}$ In the general population, the prevalence of OSA is approximately $1 \% .^{22}$ In a case-control study design, Redline et al examined the risk factors for SDB in children aged 2-18 years, and they found that the risk among obese children was increased four- to fivefold. ${ }^{5}$ However, it could be argued that such high figures overestimate the problem. In addition, although several investigators have previously noted the higher prevalence and severity of OSA among obese children, they could not find a strong relationship between the degree of obesity and the severity of respiratory disturbance during sleep. ${ }^{23-25}$ So the validity of a "straightforward" association between overweight/obesity and increased prevalence of SDB has been questioned. ${ }^{26}$ Many of these studies which have been designed to investigate SDB and obesity relationship are biased, since they have been conducted on populations of children referred for the presence of OSAS. Other have been conducted on relatively small samples. ${ }^{8,14}$ In More et al's study, it does not emerge that the group of children with SDB presents higher rates of obesity, nor does obesity influence its presentation clinically. ${ }^{27}$ Verhulst et al reported the presence of OSA in $19 \%$ of obese patients and $41 \%$ of overweight children who were referred for initial evaluation and management in an obesity clinic but did not find any correlation between BMI $z$ score and obstructive apnea-hypopnea index (OAHI). ${ }^{28} \mathrm{On}$ the other hand, the reason for such discrepant findings may reside in the limitations imposed by the reporting of obesity in terms of BMI. Clearly, BMI does not reflect body habitus and does not measure adiposity directly. Therefore, the potential mass effect of adipose tissue on the upper airway may not be reflected by traditional BMI measures, which will also fail to point toward interactions of fat tissues with developing upper airway system. In addition, More et al explained that their results had probably been influenced by the characteristics of the studied population and therefore should not be an obstacle for being attentive to the possible association of respiratory disease to obesity and its negative consequences. ${ }^{27}$ Moreover, OSAS and obesity interrelation was also demonstrated when the prevalence of SDB was examined in the general population. ${ }^{5,24,29}$

It has been postulated that decreased activity and hypersomnolence, both known to be consequences of OSA in children, may lead to obesity.

Several pathophysiological mechanisms are thought to contribute to the association of obesity and OSAS. ${ }^{8,14,30,31}$ Obesity would contribute through an increase in airway closure critical pressure and fatty infiltration of upper airway structures would favor their tendency to collapse..$^{8,14,30,32}$ The high prevalence of OSA in obese children is associated with a decrease in the cross-sectional area of the pharynx. The cause of this decrease is multifactorial. Childhood obesity is associated with narrowing of the upper airway caused by adipose tissue adjacent to the pharyngeal airway. ${ }^{6}$ In addition, there may be external compression of the upper airway by fat in the subcutaneous tissues of the neck. ${ }^{33}$ Enlarged tonsils and adenoids in obese children further decrease the cross-sectional area of the pharynx. ${ }^{21}$

The upper airway morphology is largely influenced by adenotonsillar and facial growth patterns that display discrepancies in OSA children of different ages and levels of adiposity. ${ }^{12,13}$ Therefore, the magnitude of adenotonsillar effects on childhood OSA may be altered by age and obesity. ${ }^{34}$

Adipose tissue deposited around the pharynx and neck, along with hypertrophic adenoids and tonsils, largely contribute to obstructive sleep syndrome in obese children. ${ }^{13,35}$ Physicians rationally infer that obese children, with equal adenotonsillar size, have higher apnea-hypopnea index (AHI) than nonobese children. In their study, Dayyat et al retrospectively identified two large cohorts of closely OAHI-matched pediatric patients with OSA who were also matched for age, sex, and ethnicity, and who differed only in their BMI. They found that the magnitude of adenotonsillar hypertrophy required for any given magnitude of OAHI is more likely to be smaller in obese children compared 
to nonobese children. They also concluded that increased Mallampati scores in obese children suggest that soft tissue changes and potentially fat deposition in the upper airway may play a significant role in the global differences in tonsillar and adenoidal size among obese and nonobese children with OSA. ${ }^{30}$

OSA represents the end point of the interactions between multiple factors contributing to upper airway collapsibility during sleep, which also include neuromotor responses as well as other important anatomic factors such as retrognathia and upper airway length. ${ }^{36}$

In addition to adenotonsillar hypertrophy, however, excess fatty infiltration of upper airway soft tissues along with reduced lung volume and oxygen reserve because of fat deposition around the abdomen and thorax, have been regarded as the primary factors contributing to OSAS in obese children. ${ }^{8,37}$ The proportion of respiratory disturbances during sleep was found markedly increased among obese children. ${ }^{20}$

The reoccurring desaturation-reoxygenation process has been shown to induce oxidative stress and promote the formation of reactive oxygen species which are the greatest contributors to the generation of adhesion molecules, the production of leukocytes and the activation of the leukotriene pathway. ${ }^{4,38,39}$

In particular, obesity, especially visceral obesity, is one of the major confounders in the analysis of the association between SDB and inflammation. ${ }^{40}$ Indeed, obesity directly induces a low-grade inflammatory state because adipocytes can produce numerous cytokines. ${ }^{41}$

Shen et al measured concentration of leukotriene $\mathrm{E}_{4}$ in morning urine to evaluate systemic inflammation. They found that the magnitude of inflammation as reflected by urinary $\mathrm{LTE}_{4}$ is significantly related to the severity of SDB and obesity. ${ }^{42}$ However, although inflammation plays a significant role in the pathophysiology of SDB, it cannot be determined whether that inflammatory mechanism is a cause, a consequence, or both in the disorder. ${ }^{43}$

\section{Adenotonsillectomy}

Adenotonsillectomy (A\&T) is one of the most common major surgical procedures performed in children. ${ }^{44}$ Over the past 20 years the principal indication for A\&T in children has changed from recurrent adenotonsillitis to OSA. ${ }^{8}$ It is often performed to resolve the symptoms of OSA, a condition that is more prevalent in overweight and obese children. ${ }^{45}$ Recent studies have shown that A\&T produces an improvement in the physiological parameters of sleep and a dramatic change in quality of life. Suen et al used PSG to evaluate the effectiveness of A\&T in treating OSA in 26 children. And all 26 children had a lower respiratory disturbance index after surgery, although four patients still had an respiratory disturbance index greater than $5 .{ }^{46}$ Mitchell et al studied changes in quality of life in children after A\&T for OSA documented by full-night PSG. Since total OSA-18 score was 71.4 before surgery and 35.8 after surgery, they detected improvement of quality of life after A\&T in children with OSA. ${ }^{47}$

The increasing prevalence of obesity in children and high prevalence of OSA in obese children implies that an increasing number of these children will present for A\&T. In their prospective study Kudoh and Sanai showed that A\&T was effective in decreasing irregular breathing and oxygen desaturation during sleep as measured by pulse oximetry. In their study the percentage of sleeping period with irregular breathing ranged from $10 \%$ to $85 \%$ before the operation and it decreased almost 0 after the operation. ${ }^{48}$

Soultan et al reported that treatment of OSA by A\&T in obese and morbidly obese children lead to clinical improvement of the OSA, but would not help with weight reduction and might even exacerbate obesity. They thought that attention should have been paid to reduce weight by measures such as exercise, diet, and behavioral therapy, in addition to treatment of the OSA. ${ }^{21}$ In another study, Goldstein et al reported behavioral, emotional, and improvement of quality of life after A\&T by using OSA-18 and the Child Behavior Checklist in the general population of children with OSA. ${ }^{49}$

Wang et al compared tonsil height, tonsil width, tonsil thickness, tonsil weight, and tonsil volume in 26 obese and 26 age- and sex-matched control children with SDB. And they concluded that obese children had larger palatine tonsils than the normal-weight children with SDB. This finding suggests that larger palatine tonsils may have a greater effect on upper airway obstruction in obese than in normal-weight children with SDB. ${ }^{31}$

The risk of persistence of obstructive sleep apneahypopnea syndrome in obese children after correct treatment or that of complications in the immediate postoperative period when treatment is surgical have also been widely reported. ${ }^{8,50,51}$

It was concluded that obese children with OSAS showed a dramatic improvement after A\&T and the mean reduction of AHI was greater in obese than in nonobese children although the frequency of residual OSAS was higher among obese than normal-weight children with OSAS. ${ }^{50}$ On the other hand, a recent study showed that the efficacy of A\&T for SDB was 
similar for obese and nonobese children under 10 years of age, suggesting that adenotonsillar hypertrophy may be more important than obesity in the pathogenesis of SDB in young children. ${ }^{52}$ Moreover, the frequency of postoperative AHI does not differ significantly between obese and nonobese children in the same study.

Nafiu et al have shown, in a large population of children undergoing A\&T, that overweight/obese children were more likely to have airway-related perioperative complications than their lean peers. With the growing childhood obesity, it is prudent to assume that more children presenting for A\&T may be either overweight or obese and have medical co-morbidities like diabetes, hypertension and asthma and may therefore require in-patient care..$^{53}$

In conclusion, although the risk of presence of residual symptoms of OSAS and airway-related perioperative complication in obese may be more than nonobese group, A\&T is effective to reduce obstructive symptoms and improve quality of life in obese children with OSAS.

\section{Disclosure}

The authors report no conflicts of interest in this work.

\section{References}

1. Marcus CL, McColley SA, Carroll JL, Loughlin GM, Smith PL, Schwartz AR. Upper airway collapsibility in children with obstructive sleep apnea syndrome. J Appl Physiol. 1994;77:918-924.

2. Owens J, Opipari L, Nobile C, Spirito A. Sleep and daytime behavior in children with obstructive sleep apnea and behavioral sleep disorders. Pediatrics. 1998;102:1178-1184.

3. Arens R, McDonough JM, Corbin AM, et al. Upper airway size analysis by magnetic resonance imaging of children with obstructive sleep apnea syndrome. Am J Respir Crit Care Med. 2003;167:65-70.

4. Gozal D, Kheirandish L. Oxidant stres and inflammation in the snoring child: confluent pathways to upper airway pathogenesis and end-organ morbidity. Sleep Med Rev. 2006;10:83-96.

5. Redline S, Tishler PV, Schluchter M, Aylor J, Clark K, Graham G. Risk factors for sleep-disordered breathing in children: associations with obesity, race, and respiratory problems. Am J Respir Crit Care Med. 1999;159:1527-1532.

6. Sogut A, Altin R, Uzun L, et al. Prevalence of obstructive sleep apnea syndrome and associated symptoms in 3-11 year old Turkish children. Pediatr Pulmonol. 2005;39:251-256.

7. Chay OM, Goh A, Abisheganaden J, et al. Obstructive sleep apnea syndrome in obese Singapore children. Pediatr Pulmonol. 2000;29: 284-290.

8. Tauman R, Gozal D. Obesity and obstructive sleep apnea in children. Pediatr Respir Rev. 2006;7:247-259.

9. Li AM, Au CT, Sung RY, et al. Ambulatory blood pressure in children with obstructive sleep apnea: a community based study. Thorax. 2008;63:803-809.

10. Tatlıpınar A, Biteker M, Meriç K, Bayraktar Gİ, Tekkeşin Aİ, Gökçeer T. Adenotonsillar hypertrophy: correlation between obstruction types and cardiopulmonary complications. Laryngoscope. 2012;122:676-680.

11. Gozal D, Kheirandish Gozal L. Neurocognitive and behavioral morbidity in children with sleep disorders. Curr Opin Pulm Med. 2007;13: 505-509.
12. Tatlıpınar A, Atalay S, Esen E, Yılmaz G, Köksal S, Gökçeer T. The effect of adenotonsillectomy on serum insulin like growth factors and the adenoid/nasopharynx ratio in pediatric patients: a blind, prospective clinical study. Int J Otorhinolaryngol. 2012;76:248-252.

13. Kang KT, Lee PL, Weng WC, Hsu WC. Body weight status and obstructive sleep apnea in children. Int J Obes (Lond). 2012;36:920-924.

14. Arens R, Muzumdar H. Childhood obesity and obstructive sleep apnea syndrome. J Appl Physiol. 2010;108:436-444.

15. Dayyat E, Kheirandish Gozal L, Gozal D. Childhood obstructive sleep apnea: one or two distinct disease entities? Sleep Med Clin. 2007;2:433-444.

16. Crepeau J, Patriquin HB, Poliquin JF, Tetreault L. Radiographic evaluation of the symptom producing adenoid. Otolaryngol Head Neck Surg. 1982;90:548-554.

17. Cohen D, Konak S. The evaluation of radiographs of the nasopharynx. Clin Otolaryngol Allied Sci. 1985;10:73-78.

18. Parikh SR, Coronel M, Lee JJ, Brown SM. Validation of a new grading system for endoscopic examination of adenoid hypertrophy. Otolaryngol Head Neck Surg. 2006;135:684-687.

19. Cho JH, Lee DH, Lee NS, Won YS, Yoon HR, Suh BD. Size assessment of adenoid and nasopharyngeal airway by acoustic rhinometry in children. J Laryngol Otol. 1999;113:899-905.

20. Mallory GB Jr, Fisher DH, Jackson R. Sleep associated breathing disorders in morbidly obese children and adolescents. $J$ Pediatr. 1989;115:892-897.

21. Soultan Z, Wadowski S, Rao M, Kravath RE. Effect of treating obstructive sleep apnea by tonsillectomy and/or adenoidectomy on obesity in children. Arch Pediatr Adolesc Med. 1999;153:33-37.

22. Ali N, Pitson D, Stradling J. Snoring, sleep disturbance, and behaviour in 4-5 year olds. Arch Dis Child. 1993;68:360-366.

23. Lam YY, Chan EY, Ng DK, et al. The correlation among obesity, apnea-hypopnea index, and tonsil size in children. Chest. 2006;130: $1751-1756$.

24. Marcus CL, Curtis S, Koerner CB, Joffe A, Serwint JR, Loughlin GM. Evaluation of pulmonary function and polysomnography in obese children and adolescents. Pediatr Pulmonol. 1996;21:176-183.

25. Rudnick EF, Walsh JS, Hampton MC, Mitchell RB. Prevalence and ethnicity of sleep-disordered breathing and obesity in children. Otolaryngol Head Neck Surg. 2007;137:878-882.

26. Kohler MJ, van den Heuvel CJ. Is there a clear link between overweight/ obesity and sleep disordered breathing in children? Sleep Med Rev. 2008;12:347-361.

27. More EE, Viella LC, Isern FS, Renom JA. Childhood obesity and sleep related breathing disorders. Acta Otorrinolaringol Esp. 2012;63(3): $180-186$.

28. Verhulst SL, Schrauwen N, Haentjens D, et al. Sleep disordered breathing in overweight and adolescents: prevalence, characteristics and the role of fat distribution. Arch Dis Child. 2007;92:205-208.

29. Brunetti L, Tesse R, Miniello VL, et al. Sleep-disordered breathing in obese children: the southern Italy experience. Chest. 2010;137: $1085-1090$.

30. Dayyat E, Kheirandish-Gozal L, Sans Capdevilla O, Maarafeya MM, Gozal D. Obstructive sleep apnea in children: relative contributions of body mass index and adenotonsillar hypertrophy. Chest. 2009;136: 137-144.

31. Wang JH, Chung YS, Cho YW, et al. Palatine tonsil size in obese, overweight, and normal-weight children with sleep-disordered breathing. Otolaryngol Head Neck Surg. 2010;142:516-519.

32. Young T, Peppard PE, Gottlieb DJ. Epidemiology of obstructive sleep apnea: a population health perspective. Am J Respir Crit Care Med. 2002;165:1217-1239.

33. Koeing JE, Thach BT. Effects of mass loading on the upper airway. J Appl Physiol. 1988;64:2294-2299.

34. Wing YK, Hui SH, Pak WM, et al. A controlled study of sleep related disordered breathing in obese children. Arch Dis Child. 2003;88: 1043-1047. 
35. Hsu WC, Kang KT, Weing WC, Lee PL. Impacts of body weight after surgery for obstructive sleep apnea in children. Int $J$ Obes (Lond). 2013;37:527-531.

36. Ronen O, Malhotra A, Pillar G. Influence of gender and age on upper-airway length during development. Pediatrics. 2007;120:e1028-e1034.

37. Shine NP, Coates HL, Lannigan FJ. Obstructive sleep apnea, morbid obesity, and adenotonsillar surgery: a review of the literature. Int $J$ Pediatr Otorhinolaryngol. 2005;69:1475-1482.

38. Gozal D, Kheirandish Gozal L. Cardiovascular morbidity in obstructive sleep apnea: oxidative stress, inflammation, and much more. Am J Respir Crit Care Med. 2008;177:369-375.

39. Werz O, Szellas D, Steinhilber D. Reactive oxygen species released from granulocytes stimulate 5-lipoxygenase activity in a B-lymphocytic cell line. Eur J Biochem. 2000;267:1263-1269.

40. Lui MM, Lam JC, Mak HK, et al. C-reactive protein is associated with obstructive sleep apnea independent of visceral obesity. Chest. 2009;135:950-956.

41. Visser M, Bouter LM, McQuillan GM, Wener MH, Harris TB. Low-grade systemic inflammation in overweight children. Pediatrics. 2001;107:E13.

42. Shen Y, Xu Z, Shen K. Urinary Leukotriene E4, obesity, and adenotonsillar hypertrophy in Chinese children with sleep disordered breathing. Sleep. 2011;34:1135-1141.

43. Goldbart AD, Tal A. Inflammation and sleep disordered breathing in children: a state of the art review. Pediatr Pulmonol. 2008;43: 1151-1160.

44. Rosenfeld RM, Green RP. Tonsillectomy and adenoidectomy: changing trends. Ann Otol Rhinol Laryngol. 1990;99:187-191.

45. Shine NP, Lannigan FJ, Coates HL, Wilson A. Adenotonsillectomy for obstructive sleep apnea in obese children: effects on respiratory parameters and clinical outcome. Arch Otolaryngol Head Neck Surg. 2006;132:1123-1127.
46. Suen J, Arnold J, Brooks L. Adenotonsillectomy for treatment of obstructive sleep apnea in children. Arch Otolaryngol Head Neck Surg. 1995;121:525-530.

47. Mitchell RB, Call E, Yao N, Kelly J. Quality of life after adenotonsillectomy for obstructive sleep apnea in children. Arch Otolaryngol Head Neck Surg. 2004;130:190-194.

48. Kudoh F, Sanai A. Effect of tonsillectomy and adenoidectomy on obese children with sleep-associated breathing disorders. Acta Otolaryngol Suppl. 1996;523:216-218.

49. Goldstein NA, Fatima M, Campbell TF, Rosenfeld RM. Child behavior and quality of life before and after tonsillectomy and adenoidectomy. Arch Otolaryngol Head Neck Surg. 2002;128:770-775.

50. Mitchell RB, Kelly J. Outcome of adenotonsillectomy for obstructive sleep apnea in obese and normal weight children. Otolaryngol Head Neck Surg. 2007;137:43-48.

51. Ye J, Liu H, Zhang G, Huang Z, Huang P, Li Y. Postoperative respiratory complications of adenotonsillectomy for obstructive sleep apnea syndrome in older children: prevalence, risk factors, and impact on clinical outcome. J Otolaryngol Head Neck Surg. 2009;38: 49-58.

52. Apostolidou MT, Alexopoulos EI, Chaidas K, et al. Obesity and persisting sleep apnea after adenotonsillectomy in Greek children. Chest. 2008;134:1149-1155.

53. Nafiu OO, Green GE, Walton S, Morris M, Reddy S, Tremper KK. Obesity and risk of perioperative complications in children presenting for adenotonsillectomy. Int JPediatr Otolaryngol. 2009;73:89-95.
Pediatric Health, Medicine and Therapeutics

\section{Publish your work in this journal}

Pediatric Health, Medicine and Therapeutics is an international, peerreviewed, open access journal publishing original research, reports, editorials, reviews and commentaries. All aspects of health maintenance, preventative measures and disease treatment interventions are addressed within the journal. Practitioners from all disciplines are invited to submit

\section{Dovepress}

their work as well as healthcare researchers and patient support groups. The manuscript management system is completely online and includes a very quick and fair peer-review system. Visit http://www.dovepress.com/ testimonials.php to read real quotes from published authors. 